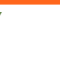

\title{
A transdisciplinary approach to disease ecology: Emerging coronaviruses
}

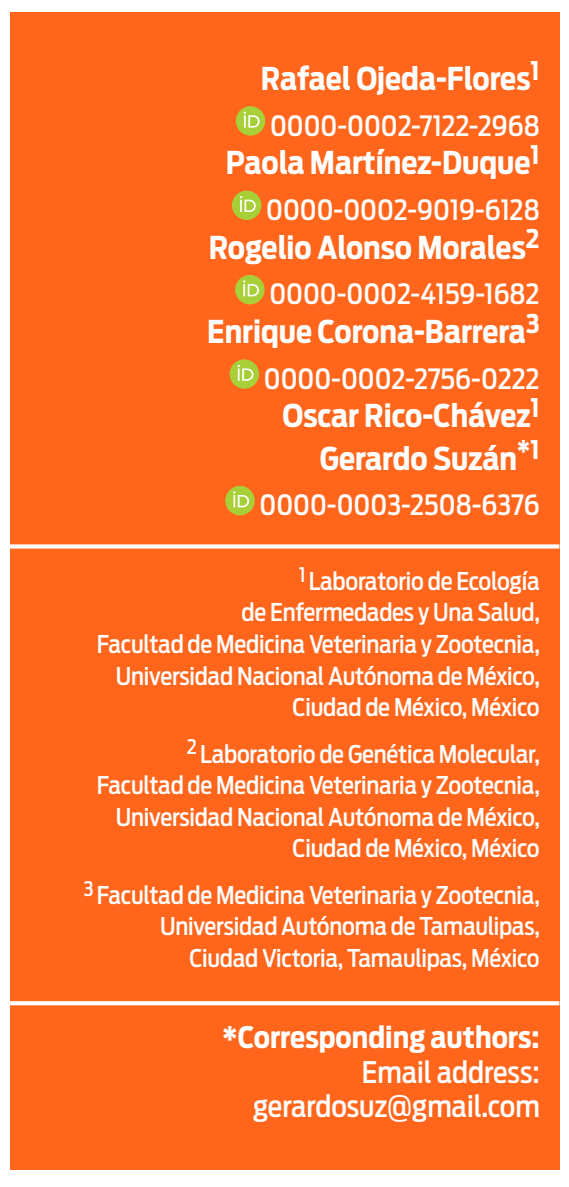

Accepted: $\quad 2021-03-11$ Published: 2021-03-26

Additional information and declarations can be found on page 17

(c) Copyright 2021 Rafael Ojeda-Flores et al. open access $\boldsymbol{\gamma}$

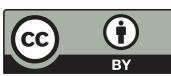

Distributed under Creative Commons CC-BY 4.0

\begin{abstract}
Humankind is currently facing the effects of an unparalleled pandemic that has impacted healthcare, social, and economic systems worldwide. Numerous studies have been published since the SARS-CoV-2 outbreak began in Wuhan, China. Most have focused on virology, epidemiology, pathogenesis, and therapeutic medicine, having been centered by reactive strategies to control the pandemic. Meanwhile, publications addressing the ecological, evolutionary, and anthropogenic drivers of virus emergence, and potential strategies to prevent future outbreaks have been sparse. Here, we highlight the necessity of complementary and transdisciplinary insight and methodologies from an integrated perspective to study emergent diseases. It is paramount to situate the consistently associated factors to understand the complexity of the current pandemic. Disease ecology can examine information to recognize the causes of emergence while appraising the role of interactions among pathogens, domestic animals, wildlife, and humans, integratively. Here we draw on a variety of disciplines and perspectives, from evolutionary biology, biogeography, ecology, molecular epidemiology and integrative health, to address the emergence of coronaviruses, with particular emphasis on SARS-CoV-2. We describe the process of the surfacing of zoonotic diseases, highlighting the interactions among wildlife, domestic animals, and humans, as well as the genetic, evolutionary, ecological, and anthropogenic processes that favor coronavirus epidemics and epizootics. We discuss specific results related to coronavirus investigations conducted in Mexico based on disease ecology methodologies. Finally, we describe alternative approaches for understanding and preventing future outbreaks and we suggest strategies to entice integrative and transdisciplinary research within the One Health/Ecohealth paradigm.
\end{abstract}

Keywords: Coronavirus; Emerging zoonoses; COVID-19; SARS-CoV-2; EcoHealth; One Health

\section{Cite this as:}

Ojeda-Flores R, Martínez-Duque P, Alonso Morales R, Corona-Barrera E, Rico-Chávez O, Suzán G. A transdisciplinary approach to disease ecology: Emerging coronaviruses. Veterinaria México OA. 2021;8(1). doi: 10.22201/fmvz.24486760e.2021.1.960 


\section{Introduction}

Humankind is currently facing the effects of an unparalleled pandemic. COVID-19, a disease caused by the Severe Acute Respiratory Syndrome Coronavirus 2 (SARSCoV-2), has gravely impacted health and socio-economic systems in practically every country in the world $(\mathrm{WHO}, 2020)$. While the critical effects of this pandemic were unexpected, the SARS-Cov-2 virus is just one of a long list of infectious agents, primarily viral, that are responsible for high impact human diseases, including acquired immune deficiency syndrome (AIDS), severe acute respiratory syndrome (SARS-CoV-1), ebola, and influenza, among others (Taylor et al., 2001; Christou, 2011 ; Plowright et al., 2017). These are all examples of recently emerged zoonotic diseases that have shaken healthcare systems at a global scale, which lead to reexamine how the entire health field should be approached, and present the need to include disciplines beyond medicine and public health, such as ecology, evolutionary biology, and anthropology, to better control and understand disease. Given that epidemics and pandemics are the result of inter-species interactions (usually among wildlife, domestic animal species, and human populations) which are influenced by ecosystem transformation and multiple sociocultural factors, there is an urgent need for transdisciplinary collaboration that allows for a better understanding and a stronger approach to each problem (Lewis, 2005; Wilcox and Colwell, 2005).

To understand the complexity of the current coronavirus emergence, it is necessary to contextualize the factors that are consistently associated with these types of events (Johnson et al., 2015; Webster et al., 2016). Zoonosis emergence includes anthropic transformation of natural ecosystems, wildlife community modification, and the alteration of the biogeographic and evolutionary history of the microorganisms that have been established in their natural hosts for millions of years (Taylor et al., 2001; Hoberg and Brooks, 2015; White and Razgour, 2020). Thus, disease ecology provides precise information to contextualize the causes of emergence and to appraise the role of interactions among pathogens, domestic animals, wildlife, and humans, in an integrated manner.

In particular, the emergence of diseases caused by coronaviruses (CoVs) resulted from increased direct and indirect interactions between humans and other animal species. Human activities have modified practically all ecosystems on the planet, which has led to changes in their structure and function, as well as changes in geographic distribution of wild species, including disease vectors and hosts, and modifications in the dynamics of infectious agents (Cunningham et al., 2017; Daszak et al., 2001). Ecosystem alterations modify patterns of occurrence and distribution of emerging infectious diseases (EIDs). This phenomenon has been exemplified by the recent emergence of all three of the novel coronaviruses (SARSCoV-1, Middle East Respiratory Syndrome (MERS), and COVID-19).

The One Health/EcoHealth perspective integrates public health, animal health, and ecosystem health, simultaneously emphasizing the necessity for international connectivity and interinstitutional collaboration, for a unifying management approach (Barrett et al., 2011; Errecaborde et al., 2019). The SARS-CoV-1 outbreak, that originated in China and that lasted eight months, infected 8,098 people and killed 774 (9.5\%) worldwide (WHO, 2003), becoming the first pandemic of the 21 st century. This, pandemic revealed interactions between different bat species, civets, raccoon dogs, and humans, that led to changes in infection dynamics (Luk et al., 2019). Later, in 2012, during the emergence of MERS, a disease associated 
with another coronavirus variant, 2,494 infected people and 858 deaths in 27 countries were recorded (WHO, 2019). These new CoVs, as the recently described SARS-CoV-2, were noteworthy because of their high pathogenicity in humans. In contrast, other previously reported CoVs infections in human populations, such as HCoV-229E, HCoV-OC43, HCoV-NL63 were considered to present low pathogenicity (Walsh et al., 2013), emphasizing particular variations.

Disease ecology is a discipline that studies the ecological and evolutionary factors that determine the occurrence, dynamics, and distribution of infectious diseases (Johnson et al., 2015). Over the past 25 years, disease ecology has allowed for the identification of the factors that determine the occurrence of emerging diseases in space and time (Cook et al., 2004; Gibbs and Gibbs, 2013; Kelly et al., 2017). This transdisciplinary approach contextualizes information related to the causes of disease emergence and appraises the role of interactions among pathogens, domestic animals, wildlife, and humans, in an integrated manner. This review aims to present a disease ecology perspective by including complementary and transdisciplinary insight and methodologies while illustrating some of their input in results related to coronavirus investigations conducted in Mexico. We draw from various disciplines, including ecology, molecular epidemiology, biogeography and evolutionary biology, to address the emergence of coronaviruses, including SARSCoV-2 (Figure 1).

\section{Coronavirus taxonomy and evolution}

The CoVs infect a wide diversity of animals, including humans. Their clinical presentation varies, affecting respiratory, enteric, renal, hepatic, and neurological tissues with fluctuating degrees of severity (Masters, 2006; Quinn, et al. 2011; Perlman, 2013). CoVs belong to the order Nidovirales, which contain the Coronaviridae and the Torovirinae families. CoVs are genetically diverse but share a large genomic size with a similar genetic organization, that encompass comparable replication strategies. However, they differ in morphology and genome length. These viruses are globally distributed, are highly infectious, and are extremely difficult to control due to their genetic diversity, short generation time, and high mutation rates. Bats and other wild species are known to have a large reservoir of previously unidentified CoVs (Anthony et al., 2017; Cui et al., 2019; Luk et al., 2019).

CoVs were initially classified into three distinct genera based on genotypic and serological characterization (CoV 1, 2, and 3; (Masters, 2006). Later, the Coronaviridae Study Group of the International Committee on Taxonomy of Viruses proposed three new genera-Alfacoronavirus ( $\alpha-\mathrm{CoV}$ ), Betacoronavirus (B-CoV) and Gammacoronavirus ( $(-\mathrm{CoV}$ )-to replace the traditional CoV 1, 2 and 3 groups (de Groot RJ et al., 2011). Recently, a new genus has been identified, the Deltacoronavirus $(\Delta$-CoV), which includes the smallest genome viruses among all CoVs (25 to 26 kb); (de Groot RJ, 2011; Woo et al., 2012a).

The $\alpha$-CoV and $\beta-C o V$ infect mammals, while the $\Upsilon$-CoV and $\Delta$-CoV mainly infect birds, though some can also infect mammals. The $\alpha-\mathrm{CoV}$ and B-CoV generally cause respiratory diseases in humans and gastroenteritis in animals. Both groups of viruses are highly pathogenic, with SARS-CoV-1, MERS-CoV and SARS-CoV-2 causing severe respiratory syndrome in humans, while the human-endemic CoVs 


\section{Zoonotic viral disease emergence}

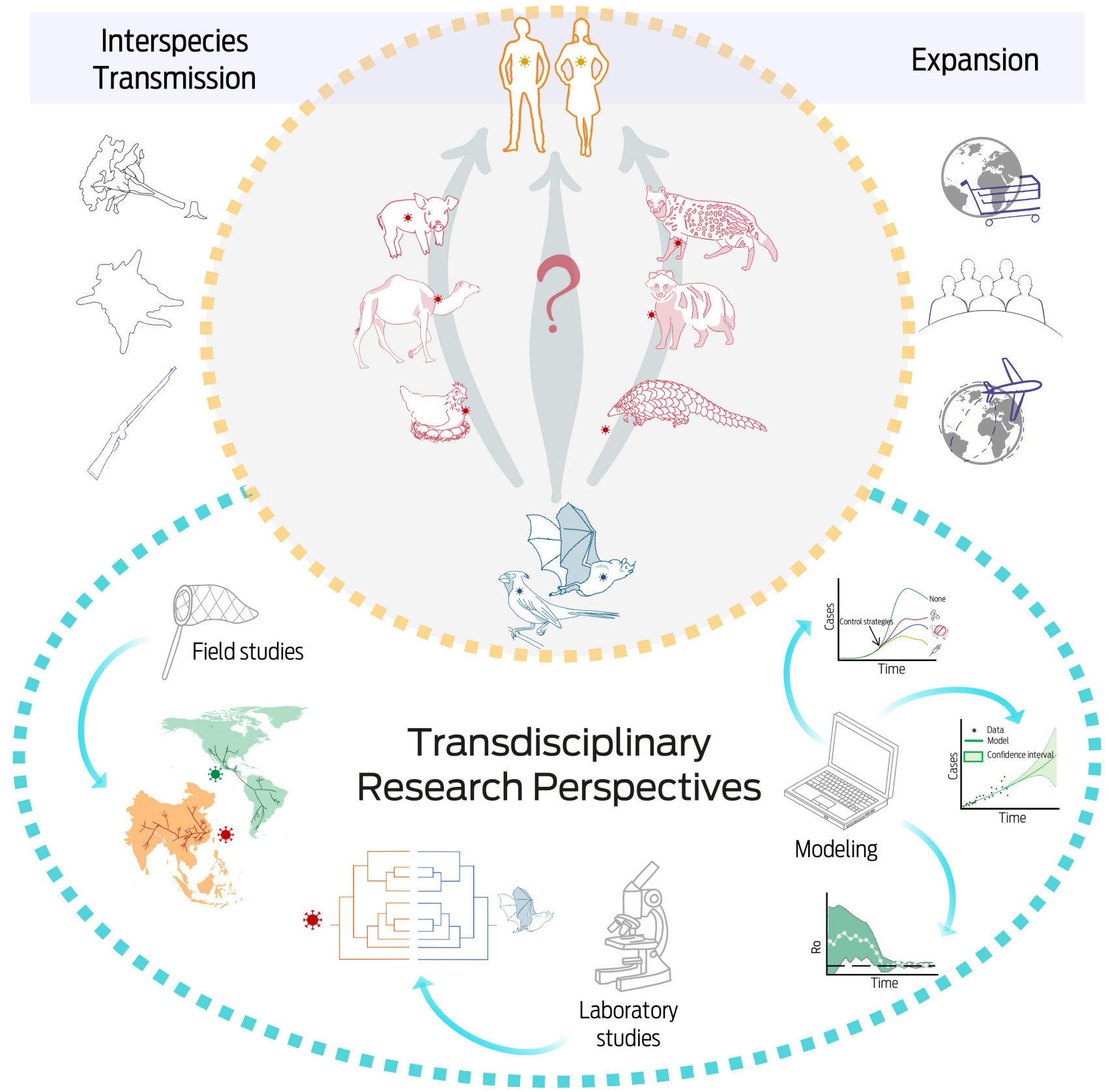

Figure 1. (Top) Emergence of zoonotic viral diseases in human populations is linked to 1) Interspecies transmission, determined by a series of processes that link the ecological dynamics of infection between wildlife reservoir hosts (blue), intermediate hosts (red), and human hosts (yellow). Biological factors of the reservoir hosts shape the susceptibility of intermediate and human hosts. The epidemiological and behavioral determinants of exposure related to ecological factors such as land use change, expansion of the agricultural and livestock boundaries, legal and illegal trafficking of wildlife species, urbanization, changes to environmental and climate conditions, and water, soil, and air pollution are also associated; and 2) Disease expansion is determined by anthropogenic, political, economic, and social forces operating at local, national, regional, and global levels. These forces are related to the increasingly globalized flow of people, products and food, as well as domestic and wild animals.

(Bottom) Understanding the complex interactions that underlie the emergence of zoonotic diseases requires a transdisciplinary approach that includes theories and methodologies from diverse fields of study, such as ecology, molecular epidemiology, biogeography, evolutionary biology, and mathematics to address the emergence of new viruses. 
(HCoV-NL63, HCoV-229E, HCoV-OC43 and HKU1) mainly induce mild respiratory conditions in immunosuppressed individuals, being the origin of close to 15\% of seasonal colds. Certain human-endemic CoVs can also cause severe infections in infants, young children, and the elderly (Masters, 2006; Perlman, 2013).

In general, CoVs found in humans originated in animals, with SARS-CoV-1, MERS, SARS-CoV-2, HCoV-NL63 and HCoV-229E coming from bats, while HCoVOC43 and HKU1 probably emerging from rodents (Anthony et al., 2017; Cui et al., 2019). Based on molecular clock analyses, it has been estimated that the most recent common ancestor of all CoVs originated approximately 8, 100 years ago ( $\mathrm{YoE}$, years of evolution), and those of the $\alpha-\mathrm{CoV}, \mathrm{B}-\mathrm{CoV}, \Upsilon$ - $\mathrm{CoV}$ and $\Delta$-CoV encompass approximately $2400 \mathrm{YoE}, 3300 \mathrm{YoE}, 2800 \mathrm{YoE}$, and $3000 \mathrm{YoE}$, respectively. It has been proposed that bats and birds are the ideal host for CoVs, with bats giving rise to the $\alpha-\mathrm{CoV}$ and $\mathrm{B}$-CoVs, and birds originating the $\Upsilon$-CoV and $\Delta$-CoV groups (Woo et al., 2012b). CoVs that affect humans are found within the $\alpha-\mathrm{CoV}$ and $\mathrm{B}-\mathrm{CoV}$ genera (Luk et al., 2019). There are four distinct sub-genera in the ß-CoV genus: ßa, $B b, \beta c$, and $B d$. In particular, the two SARS CoVs that affect humans are found in the subgenus $B b$, while MERS-CoV is classified within the $ß c$ subgenus. CoVs described in bats belong to the $\mathrm{Bb}, \mathrm{BC}$ and $\mathrm{Bd}$ subgenera, as well as to a specific clade of the $\alpha$-CoV genus (Figure 2).

It has been shown both experimentally and in nature, that CoVs have a genetic divergence that favors host and niche switching and adaptation (Jackwood, 2006; Woo et al., 2009, 2006). In particular, CoVs exhibit continuous genetic recombination through the genomic mechanism of template switching (Woo et al., 2006). These changes generate point mutations at a similar speed to other RNA viruses, including type A influenza viruses (Brian and Baric, 2005). This tendency for recombination and high mutation rates increase likelihood for regular host switching between animals and humans and multi-host capacity, leading to potential epidemics and epizootics.

\section{Coronavirus structure and molecular biology}

CoVs are enveloped viruses with a positive-sense single-stranded RNA genome and a helical nucleocapsid. The CoVs genome size ranges from 26 to 32 kilobases, the largest among all RNA viruses. The shape of the virion is pleomorphic, varying in diameter from 80 to $100 \mathrm{~nm}$. These viruses have characteristic projections on their surface (spikes), which are reminiscent of the solar corona when observed by electron microscope imaging, hence acquiring their name (Jackwood, 2006; Masters, 2006).

The genomes of all CoVs have a 5' methylated cap, a 5'- UTR leader region, and a UTR region with a polyadenylated tail at the $3^{\prime}$ end. The main proteins encoded by the CoV genome from the $5^{\prime}$ end are: the viral polymerase, the polyprotein replicase/transcriptase (which is coded by Open Reading Frames, ORF 1a and 1b, that occupy the first two thirds of the genome, and are cut to form non-structural proteins), the hemagglutinin-esterase ( $\mathrm{HE}$, which is present in some viruses), the spike glycoprotein (S, located on the surface of the virus), a small envelope protein $(E)$, a membrane integrated glycoprotein $(M)$, and the nucleocapsid protein ( $N$, which is closely associated with the viral RNA). Interspersed between these reading frames are additional reading frames coding for accessory proteins that determine 


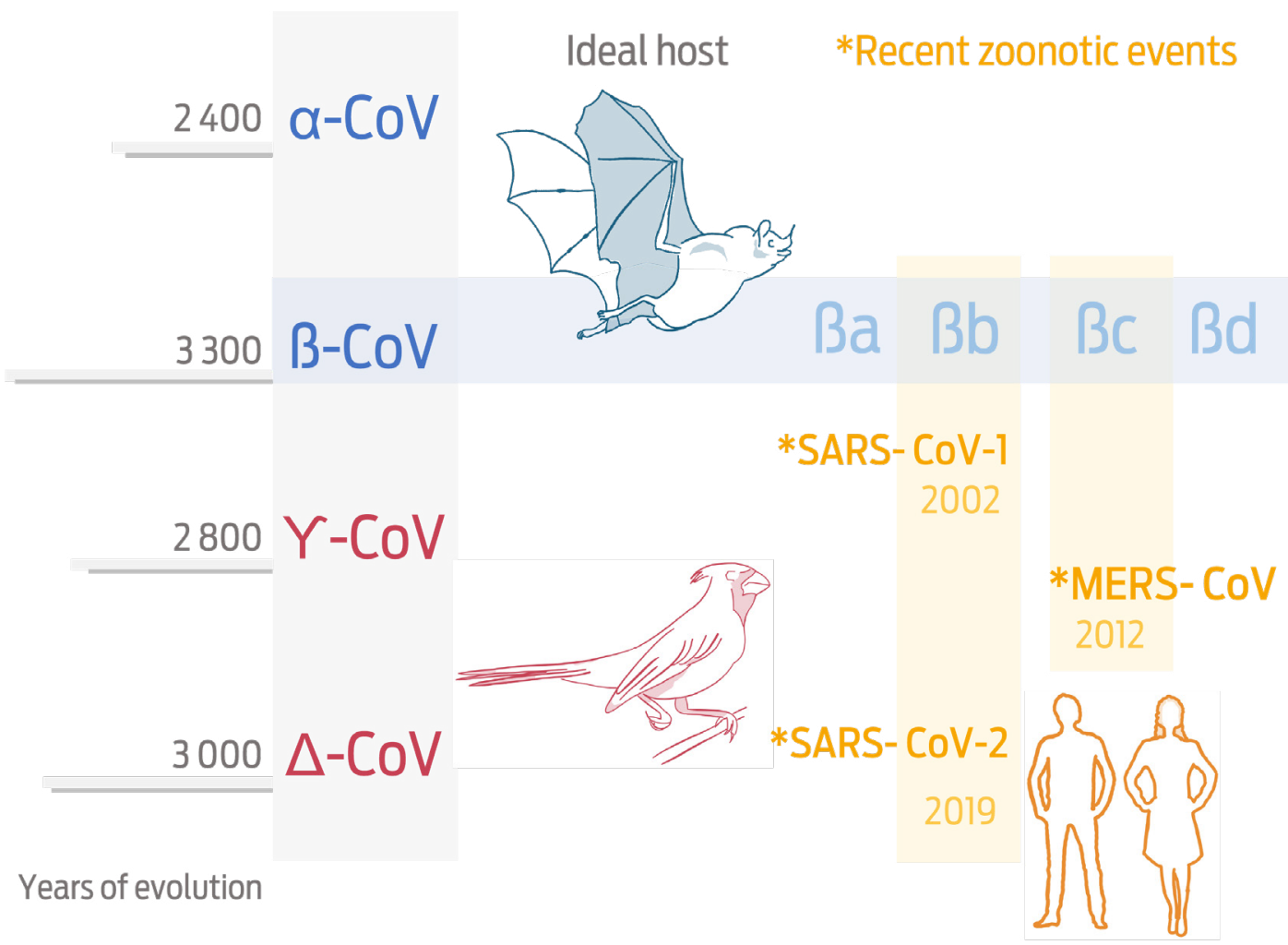

Figure 2. Bats are proposed as ideal host for $\alpha$-CoVs and $\beta$-CoVs, and birds for $\Upsilon$-CoVs and $\Delta$-CoVs. CoVs that affect humans are found within the $\alpha-\mathrm{CoV}$ and $\beta-\mathrm{CoV}$ genera with four distinct sub-genera: $\beta a, B b, \beta c$, and $\beta d$. The two SARS CoVs that affect humans are only found in the subgenus $B b$, while MERS-CoV is part of the $B c$ subgenus.

a number and functions that are unique to each specific coronavirus (Jackwood, 2006; Masters, 2006) (Figure 3).

At a molecular level, CoVs employ various unusual strategies to complete a complex gene expression program. Their replication involves ribosomal frameshifting during translation of the genome, synthesis of multiple genomic and subgenomic RNA species, and the assembly of progeny virions via a pathway that is unique among enveloped RNA viruses (Brian and Baric, 2005; Masters, 2006). In infected cells, CoVs use a nested transcription strategy in which gene expression occurs through the synthesis of several $3^{\prime}$-coterminal subgenomic mRNA. This unique strategy was recognized as distinctive for the establishment of the order Nidovirales (from the Latin, nidus, nest) (de Vries et al., 1997; Jackwood, 2006; Masters, 2006).

The $\alpha$-CoVs do not have the HE protein; the M protein is N-glycosylated, and the $S$ glycoprotein is not cut. Most of the viruses from the B-CoV do have the HE protein; the $M$ protein is O-glycosylated, and the $S$ glycoprotein is cut into two subunits. The $\mathrm{Y}$-CoV lack HE protein; the M protein is $\mathrm{N}$-glycosylated, and the $\mathrm{S}$ glycoprotein undergoes proteolytic cuts (Cui et al., 2019; Jackwood, 2006; Woo et al., 2012b). The $\Delta$-CoVs have a single protease domain, similar to papain at gene nsp3; the accessory ORF NS6 gene (ORF) situated between genes M and N), and a variable number of additional accessory genes (up to four) (Woo et al., 2012b). 

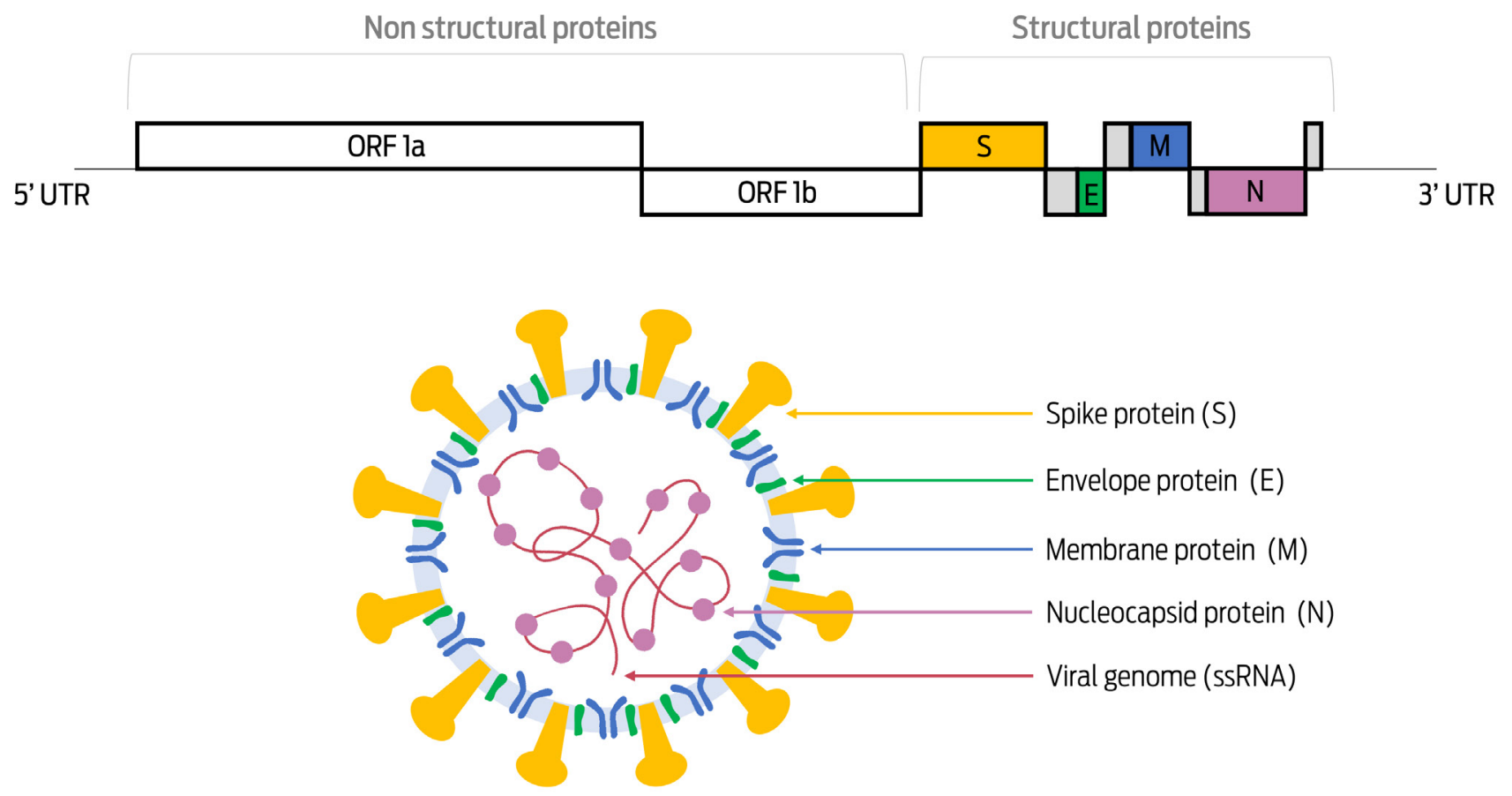

Figure 3. (Top) General schematic representation of the genomic organization of coronaviruses.

(Bottom) Schematic diagram of a coronavirus virion and its primary structural proteins.

\section{Factors that favor infectious disease emergence: the coronavirus epidemics}

In addition to recognizing the particular features of coronaviruses, it is necessary to describe additional factors that favor viral emergence, as well as the associated ecological and anthropogenic processes, that are critical to understand disease development.

\section{The zoonotic viral emergence process}

The diseases caused by novel CoVs during the 21 st century are representative of zoonotic transmission from wild animal species. While the source of SARS-CoV-2 has not been 100\% confirmed, it is highly probable that like SARS-CoV-1 and MERS, the origin of SARS- CoV-2 is associated with bats (H. Zhou et al., 2020; P. Zhou et al., 2020) and probably pangolins (Lam et al., 2020; Xiao et al., 2020).

The ecological process of a zoonotic virus emergence is complex, since it involves intrinsic factors of both a particular virus and its host species, as well as extrinsic factors related to the environment in which the virus and hosts interact (Boots et al., 2009; Day and Proulx, 2004). To understand this process, it is necessary to acquire information related to viral evolution mechanisms, permanence of the virus in natural hosts, and transmission among taxonomically distinct species, like humans. It is also necessary to understand how the disease process arises and how, through repeated infections in the new species, the virus becomes capable to 
generate sufficient morbidity or mortality rates to be detected and characterized as a new health problem of local, regional, or global importance.

The ecological process of viral emergence must go through four fundamental stages, the first two being a prerequisite for the emergence of a new disease. First, contact must occur between the natural reservoir and a new susceptible species. Second, there must be an interspecies transmission, in which the virus crosses a species barrier and completes its cycle of infection within a new host. In some diseases, such as the Hantavirus pulmonary syndrome for example (Ermonval et al., 2016), the new host may become infected but cannot transmit infection, becoming an accidental host, and limiting infection to this single individual. Some infections may require the participation of several species as intermediate hosts, as is the case of camels and alpacas in MERS, or of civets in SARS-CoV-1 (Gong and Bao, 2018). In other instances the reservoir can transmit the disease directly to the new species, without the need for an intermediate host. The role of intermediate hosts in the emergence of COVID-19 is not yet clear, though the Malayan Pangolin (Manis javanica) has been purported as a possibility (Lam et al., 2020; Liu et al., 2019; Xiao et al., 2020). It is also important to recognize that intermediate hosts can maintain diseases caused by CoVs, while being reservoirs that favor viral recombination, hence having the capacity to infect other species, such as humans (Mohd et al., 2016; Rabaan et al., 2017).

The third stage of the viral emergence process is sustained transmission among individuals of the new species. In the SARS-CoV-2 situation for instance, the individual or individuals that were in contact with the reservoirs and became infected, were also able to transmit the agent to their conspecifics. The fourth and final stage of disease emergence is genetic adaptation following transmission. The evolutionary adaptation of the virus and the new host (and vice versa) results in a new virus that is qualitatively and quantitatively distinct from the original virus (Agudelo-Romero et al., 2008; Cressler et al., 2016).

\section{Ecosystem transformation}

Anthropogenic ecosystem transformation includes land use change, expansion of the agricultural and livestock boundary, urbanization, changes to environmental and climate conditions, legal and illegal wildlife trafficking, as well as water, soil, and air pollution (Ellis et al., 2010). All of these factors modify the interactions between organisms within the ecosystem and broaden the contact interface between wildlife, domestic animals, and humans (Mackenstedt et al., 2015; Patz et al., 2004). Increasing the rates of inter-species contact also alters the behavioral and population ecology of the hosts, as well as that of their infectious agents, and the characteristics of the host-virus interaction (Daszak et al., 2000; Jones et al., 2008; Morens et al., 2004; Morse, 1995). Therefore, anthropogenic activities can have a profound impact on the assembly of host species communities (i.e., diversity, composition and abundance), which can subsequently impact pathogen prevalence (Johnson et al., 2015).

To study how diseases are maintained within ecosystems, disease ecology incorporates ecological and phylogenetic indexes, such as taxonomic and phylogenetic beta diversity metrics, that are used in community ecology to understand the interactions within multi-host and multi-pathogen systems (Behdenna et al., 2019; 
Woolhouse et al., 2001). These indexes are also used to measure changes in the viral composition within the ecosystem community, including CoVs, considering hosts at different spatial scales, over several environmental gradients (Anthony et al., 2013; Rico-Chávez et al., 2015; Nieto-Rabiela et al., 2019, 2018). A Mexican study described a strong relationship between bat diversity and richness of four viral families of medical importance (Hantavirus, Paramyxovirus, Pegivirus and Coronavirus) in three regions of the country. Results of this work suggest that generalist bat species, namely species that are not affected by habitat modifications, are related with more viral families than bat species affected by habitat modifications (Rico-Chávez et al., 2015). Thus habitat modification can bias the composition of the potential host communities, at different taxonomic and phylogenetic levels, toward species that tend to carry more viruses, generating zoonotic disease emergence risk areas, often near human populations.

Focusing on spatial scales has allowed for the identification of space and timeframe levels where infections operate in multi-host systems. Most of the processes that favor a viral taxonomic jump occur at different spatial scales and are contextspecific. Nonertheless, identifying the scale at which an infectious disease operates is fundamental for its prevention and modeling (Milholland et al., 2018). The landscape scale is where most of the interaction processes occur, such as inter-species contact or community composition modifications, and also where the human-wildlife-domestic animal interface takes place. This scale can therefore be considered as the scale of operation of emerging zoonotic diseases, yet it is seldomly evaluated in infection modeling and simulation (Suzán et al., 2015).

Nowadays it has become increasingly crucial to comprehensively understand how food production methods, land-use planning, and other human activities can affect spatial patterns and ecological processes in ways that impact infection emergence. Landscape ecology studies of interactions between flora and fauna, as well as social components, including spatial and temporal variation, are imperative to adequately assess disease emergence scenarios. Addressing biotic and abiotic interactions from an earth science perspective and characterizing the geometric conformation, functionality, and heterogeneity of the landscape becomes essential (Wiens et al., 1993; Urban, 2006). Landscape ecology is a recent discipline, whose development has been largely driven by technological advances in remote sensing. In the context of infectious disease, there is a growing number of studies that use the characterization of landscapes to relate landscape transformation to infection dynamics (Cobb et al., 2012; Gottdenker et al., 2014). The analysis of landscape heterogeneity and connectivity show how dynamic transmission scenarios can be and how infections can persist.

Anthropized environments are characterized by alternating environmental heterogeneity and homogeneity which often include combinations of grazing pasture, crop fields, fragments of natural and secondary vegetation of variable size and shape, in rural, semi-rural, suburban and urban human settlements. Each of these landscape variables has been shown to impact disease transmission. The shape, size, and connectivity of environmental patches affect infection dynamics. Empirical studies in Costa Rica (Daily et al., 2003), Venezuela (Utrera and Duno, 2007), the United States (Diffendorfer et al., 1995), Chile (Torres-Pérez et al., 2004), Panama (Suzán and Ceballos, 2005) and Paraguay (Yahnke, 2006), as well as studies at continental and global scales (Rubio et al., 2014; López-Pérez et al., 2019) have 
shown that habitat loss and landscape modification favor pathogen reservoir species that tolerate fragmented environments. For infectious agents associated with bats, different land use types and landscape variations, including linear fragmentation and edges, favor viral reservoir species (Rico-Chávez et al., 2015; LanzagortaValencia et al., 2019) and a differential distribution of viral diversity, including that of CoVs that we have reported in southern Mexico (Anthony et al., 2013; Rico-Chávez et al., 2015).

The occurrence of emerging disease outbreaks with high human health impact, has been linked to proximity of people and animals. The emergence of MERS for example is attributed to contact between people and domesticated camels, which cohabitate with other species of domestic animals as well as bats that live in nearby refuges (Goldstein and Weiss, 2017; Smith and Wang, 2013). Similarly, appearance of, the Hendra virus in people in Australia in 1994 was associated with bat (genus Pteropus) transmission to horses, and then from horses to humans (Halpin et al., 2000). Also, , the Nipah virus in several Asian countries emerged from interactions between bats, pigs, palm plantations, and humans. This process was favored by ecosystem fragmentation and niche invasion (Kulkarni et al., 2013). The case of SARS-CoV-2 is similar. Phylogenetic analysis of viral variants suggest that bats are the primary source of this CoV (H. Zhou et al., 2020; P. Zhou et al., 2020). While the precise location and mechanisms of transmission are not yet known, it has been suggested that Malayan Pangolins (Manis javanica) acted as intermediate hosts, contracting the virus from bats, then transmitting the infection to humans (Lam et al., 2020). The interaction among these three species is likely linked to a confluence of conditions that favored more frequent encounters in the human-animal interface, ecosystem fragmentation and deterioration, illegal markets, niche invasion, poaching, and consumption of bushmeat without sanitary regulations (VanWormer et al., 2013; Hassell et al., 2017; Paige et al., 2017). Landscape ecology assesses landscape transformation and infection dynamics, including sociocultural consumption habits and other conducts, as well as aspects of utilization of natural resources. These scenarios, where biological and cultural processes occur, signify the ideal landscape scale for modeling multi-factor scenarios that resemble the current pandemic emergence events.

\section{Wildlife consumption and legal and illegal trafficking}

Every year, hundreds of thousands of plants, animals, as well as their derivatives are legally traded to satisfy food demand of different societies (Rosen and Smith, 2010). Meanwhile, the illicit wildlife trade is considered the second most lucrative illegal market after drug trafficking (Wyler and Sheikh, 2016). The unlawful nature of this trade prohibits a full knowledge of its magnitude, and hinders the understanding of its impact on ecosystems and health. Many pathogens have been introduced into new ecosystems and communities when host species are transported, legally or illegally, to sites out of their original distribution boundaries. Introduced pathogens can potentially lead to local species extinctions, including endemic and/ or endangered species, and can trigger ecosystem collapse. Pathogens that have been repeatedly mobilized by this mechanism include rabies, Bacillus anthracis, Mycobacterium tuberculosis, Echinococcus spp. and Leptospira spp., among others (Pavlin et al., 2009). 
Systematic monitoring of species trafficking in markets in Guangzhou, China for instance have revealed constant trading of masked palm civets (Paguma larvata), ferret-badgers (Melogale spp.), wild boar (Sus scrofa), and several endangered species (Lau et al., 2010). After the emergence of SARS-CoV-1 in 2003, 838,500 wildlife animals were confiscated from markets in this city (British Broadcasting Corporation, 2003). It has been recognized that this type of trafficking favors interactions among species, such that wild-life trade markets serve as points of contact that facilitate taxonomic jumps of different infectious agents to new hosts. The origin of the Human Immunodeficiency Virus is also attributed to human consumption of non-human primates (Gao et al., 1999). Similarly, the recent Ebola outbreaks are associated with human consumption of great apes (Leroy et al., 2004), and the SARS-CoV- 1 has been related to international trade of small carnivores and bats (May et al., 2004; Lau et al., 2005).

Consumption of bushmeat is known to increase food availability for low-income human communities in many countries around the world, particularly in Africa (Friant et al., 2020). Unfortunately, this practice is not regulated, and endangered species are often overexploited. Certainly, a report to to the Convention on International Trade in Endangered Species of Wild Fauna and Flora (CITES), informed of the trade of pangolins (mostly from Asia), mainly for their skin. The report estimates that from 1977 to 2014, approximately 50,000 pangolins were trafficked, most being of the Manis javanica species (Heinrich, 2017). This is the same species that has been associated with the transmission of SARS-CoV-2. Current data estimate that nearly 900,000 pangolins have been traded across Southeast Asia in the past two decades (WHO, 2020).

\section{Wildlife and emerging coronaviruses Coronaviruses in wildlife}

The human epidemic outbreaks of SARS-CoV-1 (and MERS-CoV) in China (20022003) and Saudi Arabia (2012), (Drosten et al., 2003; Zaki et al., 2012), have led to an increased interest in this viral family and its relationship to wildlife on a global scale. At the beginning of the SARS-CoV- 1 outbreak, the viral reservoir in wild animal species was unknown, and in initial studies, the palm civet (Paguma larvata), the raccoon dog (Nyctereutes procyonoides) and the Chinese ferret-badger (Melogale moschata) were proposed as the virus natural hosts (Song et al., 2005; $\mathrm{Xu}$ et al., 2004). Ensuing field studies and extensive scale phylogenetic analyses revealed that horseshoe bats (Rhinolophidae) acted as the natural reservoir of SARS-CoV- 1 , and that the civet, raccoon and ferret were intermediate hosts that facilitated amplification of the virus (Lau et al., 2005; Li et al., 2005). The first CoVs report in bats came from China in 2005, as part of a monitoring program established to determine viral circulation in wildlife (Poon et al., 2005). Since then, a growing number of wildlife studies, mainly in bats, have increased knowledge of Covs diversity, allowing for new viral species discoveries in a wide range of mammal and avian hosts.

Bats appear to be particularly important reservoirs for CoVs and have been identified as natural hosts for several CoVs genoypes after the SARS epidemic (Drexler et al., 2014). Moreover, bat CoVs are more diverse than those identified in 
other wild mammal species; bats being natural hosts to the largest diversity of CoVs described to date (Drexler et al., 2014; Anthony et al., 2017). Consequently, search efforts have increasingly focused on bats, as they continue to be established as reservoirs for numerous viral agents. The abundant descriptions of new viruses in bats and other wild animals have drastically changed our perception of the relevance of reservoir species in emerging zoonoses (Ang et al., 2018; Bengis et al., 2004; Hayman, 2016). However, knowledge of the ecological and evolutionary factors that affect viral diversity is often overlooked. For example, there is a geographic bias in CoVs studies in bats, with a notable lack of information in high biodiversity regions including Africa, Asia, and Latin America (Drexler et al., 2014). Given that bats are central CoV reservoirs, an entire line of research in this mammal species has become critical to understand factors that affect viral prevalence in wildlife populations. Certainly, it has been suggested that host ecology could be determinant in defining the degree of susceptibility and viral prevalence, which could limit or favor viral transmission within or between different species (Luis et al., 2013).

\section{Coronavirus evolutionary patterns}

Before the SARS-CoV-1 epidemic in 2002, most of the scientific knowledge regarding CoVs was the result of animal health research, mainly in domestic animals, leaving ecological and evolutionary aspects practically unexplored. It has however become increasingly evident that phylogenetic and coevolutionary studies of emerging pathogens are central in identifying the origin of the virus, its current distribution and associated host species, as well as for providing the bases for understanding viral ecology and zoonotic potential in different risk areas (Davies and Pedersen, 2008; Lei and Olival, 2014; Chu et al., 2011).

After the SARS-CoV-1 epidemic, nine new species of CoVs were identified in hosts where they had not been previously described. Given that the interactions between infectious agents and species that act as their natural reservoirs occur over evolutionary time scales (millions of years), development of a large diversity of well-adapted pathogens can take place (Carroll et al., 2007). For CoVs in particular, most genotypes naturally infect a single host species or a small number of closely related species. High genotype diversity of CoVs is mainly due to their elevated mutation rate $\left(0.80-2.38 \times 10^{3}\right.$ mutations per site per year) and their evolutionary dynamics, including recombination and other viral strategies (Drexler et al., 2014; Durães-Carvalho et al., 2015). These characteristics could explain the proposed coevolutionary relationship between CoVs and different species of bats (Anthony et al., 2013; Cui et al., 2019).

Bat CoVs have a large genetic divergence and are the oldest identified CoVs considering the evolutionary scale. Interestingly, it has been shown that CoVs present stable viral loads in populations of bats, while an epidemic population growth can be seen in other host species (Vijaykrishna et al., 2007; Gloza-Rausch et al., 2008; Pfefferle et al., 2009). Given that there is a close bat-CoV relationship between specific species of both types of organisms, it has been important to consider how the diversity and distribution of bat species affects the richness and diversity of CoVs. In the Americas, for example, the relationship between similar CoV genotypes and closely related bat species has supported the hypothesis of coevolution (Ojeda, 2015). This association has been observed when comparing CoV 
genotypes present in populations from geographically distant areas (Gloza-Rausch et al., 2008; Tang et al., 2006). Nonetheless, reports also show that within the same refuge, two host species from different families of bats can harbor the same CoV genotype, contrary to the theory of host specificity (Osborne et al., 2011). The coevolutionary relationship found between bats and CoV populations in Mexico, indicates that hosts drive CoV selection and evolution, highlighting the importance of studying these evolutionary associations.

Among the different approaches pertinent for the study of the emergence of zoonotic diseases, focusing on evolutionary associations between host and viruses could thus be important for viral reservoir identification and related inter-species jumps. This methodology considers that emerging viruses circulating in new species share sufficient similarity with the viruses circulating in reservoir communities.

In Mexico, monitoring bat CoVs has revealed a coevolutionary relationship in which host species act as drivers for Covs selection and evolution, such that the host geographic distribution pattern could determine the distribution and epidemiology of the viruses (Anthony et al., 2013). For example, a bat related CoV monophyletic group has been identified in Mexico City (located at the center of the country), which has different genome sequences than those identified for a group in the southeast of the country, suggesting that the difference in phylogenetic composition of CoV communities could reflect the variations in the composition of the host communities distributed in the regions of the Nearctic, Neotropic, and transition zone located in Mexico (Ojeda, 2015).

Mexico has an extraordinary bat diversity and abundance that are unusually greater than those found for other groups of mammals. In 2013, eight genotypes of $\alpha$-CoVs and four of $\beta$-CoVs detected in Mexican bats showed phylogenetic distinctiveness, suggesting that the host species could act as key drivers of the CoV evolution (Anthony et al., 2013). Interestingly, a 6.9\% CoVs prevalence was detected in bats sampled in the transition zone located in Central Mexico in 2015. Since the most abundant captured bat species in the sample coincided with the highest prevalence, this parameter could be partly explained by sampling bias. An alternate explanation could however be that gregarious species (the most abundant in this region) with higher rates of contact among individuals could have higher $\mathrm{CoV}$ prevalences, especially when considering species from large, dense colonies (Ortega and Arita, 1998; Schountz, 2014; Plowright et al., 2015; Martínez-Duque, 2017). CoVs positive individuals from species with lower abundances within the sampled refuge were also detected, indicating that high host population density is not required for CoVs to circulate within a bat population. This suggests that $\mathrm{CoV}$ genotypes may persist if adapted to a host population with consistent and frequent bat reproductive rates (Papkou et al., 2016). Hence, an integrated approach is required to understand aspects of ecology and evolution in local bat-CoVs dynamics.

\section{Coronaviruses biogeographic patterns}

Due to the variation in ecological processes and dynamics, the drivers of disease emergence also present spatial variations, such that the environmental and biogeographic characteristics of a region are significant determining factors (Peterson et al., 2004; Scheiner, 2009; Reperant, 2010). In this sense, the interaction between the virus, the host, and the environment, occur on an ecological time scale 
(hundreds of years), which leads to the confrontation to constant changes in short time periods. This causes alterations at different temporal and spatial scales with implications for both ecological and evolutionary processes (Carroll et al., 2007).

Based on our previous results (Anthony et al., 2013), and given that bat studies in the Americas have been linked to CoV presence in relatively few species (less than 15\%), we studied the CoV-bat relationship in terms of its biogeographic affinity, comparing the CoV-bat local associations between the Neotropical region and the Nearctic - Neotropic transition zone. We found that the CoV geographic distribution seems to be influenced by host distribution, meaning that the viral genotype allocation could be mostly restricted to the host species distribution area (MartínezDuque 2017). The identification of a high genotype divergence of CoVs in restricted geographic areas highlights CoVs adaptability towards different bat species. Since both host and habitat attributes are strong selective drivers in CoV evolution, even in geographically separated populations, the combination of evolutionary and biogeographic approaches is useful to broaden the CoVs study framework. While it is important to investigate coronavirus diversity in bats, it is also important to remember that the majority of viruses they carry will not pose any clinical risk, and bats should not be stigmatized ubiquitously as significant threats to public health.

\section{Research perspectives}

\section{Community-level viral diversity}

Measuring the genetic diversity of viruses is essential to understand their evolutionary dynamics, but reconstructing the genetic characteristics of a population, such as the composition and relative frequencies of viral genomes, represents a problem at a different scale from the experimental design to the analysis of information (Iwasa et al., 2004). The community level approach has been employed for the study of infectious diseases at a macroecological scale, requiring the identification of geographic distribution patterns of organisms (host, vectors and pathogens) involved in the ecology of a disease (Murray et al., 2015). Currently, the use of distribution models as a tool for identifying disease emergence in risk zones continues to increase, and advantages and disadvantages of the use of these models have been described (Anderson, 2012; Beck et al., 2014). The accuracy of distribution models depends strongly on data availability and quality, and lack of information can seriously bias their performance (Anderson, 2012; Beck et al., 2014). Nonetheless, distribution model outcomes help to determine priority areas to investigate CoVs, increasing efficient use of available resources and directing efforts towards regions where information is most needed.

Network theory is a useful community level approach that has been recently incorporated to facilitate the study and description of complex systems, as the associations between viruses and hosts, considering their respective diversities. Efforts have been undertaken to describe CoVs distribution patterns at a macroecological scale to detect communities within the network, represented as a set of closely related nodes. A global study of CoVs distribution revealed that these viruses show a high level of continental modularity. That means that CoVs genotypes are not shared among continents, with the exception of Asia and Africa, where only two are common to both continents (Anthony et al., 2017). In a recent study using 
network theory to estimate viral diversity and to describe the relationship of Covs with other viral families and their hosts, we found that the CoVs have high centrality values, which are higher than those found for other commonly studied viruses such as Lyssavirus and Paramyxovirus. This is probably due to the large diversity of host species with which CoVs have been associated, as well as to a high host specificity (Nieto-Rabiela et al., 2019). In terms of disease ecology, the community level approach permits to explore host-host, virus-host and virus-virus interactions, by measuring network attributes, such as connectivity. Network analyses thus offer the opportunity to recognize highly diverse viruses and hosts based on a high degree of connectedness. This approach can be used to better understand of how interactions take place within pathogen communities, how hosts are connected with pathogens, their preferred associations and patterns of pathogen transmission. It is thus a useful tool for identifying hosts and viruses of potential importance in the zoonotic disease transmission dynamics.

\section{Molecular analyses}

Depending on the scale of the study, number of species (phylogenetic), or involved population (phylogeographic), molecular tools and phylogenetic analyses allow for the development and testing of hypotheses related to the dynamics of viruses and their hosts at macro- and micro-ecological scales (Denef et al., 2010; Hunt et al., 2008). These techniques are necessary to broaden our understanding of the mechanisms involved in the emergence of CoVs. Through the molecular identification and description of the evolutionary history of microorganisms, it is possible to establish the origins and patterns of dispersal and evolution involved in the emergence of disease in different populations. In relation to SARS-CoV-2 specifically, this approach is being intensively explored, mostly in relation to the evolution of the virus in the human population throughout different regions, and as a function of the time of local, regional, and worldwide spread (da Silva Candido et al., 2020; Deng et al., 2020; Lemey et al., 2020). Approaches based on molecular epidemiology have allowed for genetic and functional data analyses on SARS-CoV-2 with the aim of characterizing its evolutionary mechanisms, pathogenicity, and response to vaccines, as well as possible antiviral medications that are under development (Liu et al., 2019; Amanat and Krammer, 2020; Mavian et al., 2020). The molecular identification and characterization of CoVs in wildlife can also be useful for reservoir host identification and possible intermediate host SARS-CoV-2 association. An integrated evaluation of CoVs that are closely related to SARS-CoV-2 and that circulate in wildlife is essential to understand specific viral functions. While relevance of establishing the exact mechanisms by which SARS-CoV-2 arose and evolved in human populations through natural selection by molecular analyses is important, continuous monitoring of COVID-19 in humans and other animals is also of the utmost importance.

\section{Conclusions}

The current COVID-19 pandemic highlights an imperative need to improve the healthcare and environmental sectors, as well as the relationship of humankind 
with nature. The emerging One Health/Ecohealth paradigm must be transdisciplinary, encouraging intersectoral strategies at a national level, as well as international collaboration. Rethinking conservation, food production, and economic models that relate human and other species to natural resources has now high priority.

Disease ecology provides an integrated framework to develop novel research for infectious disease dynamics, leading to a better understanding of pathogen, wildlife hosts, domestic animals, and human interactions, that can only be accomplished by identifying the causes and processes associated with disease emergence. Transdisciplinary work that integrates biological, physical, and social sciences is essential for developing innovative and adaptive prevention and control strategies. A constant research and monitoring of potential emerging viruses at the interface among wildlife, domestic animals, and humans is also required. Simultaneously, evaluation of environmental and landscape characteristics that favor emerging infectious diseases, including land use and widening of the agricultural border, environmental degradation, and socioeconomic conditions, is fundamental to the development of adequate responses to future crises. Multi-host-multi-pathogen model integration in the study of CoVs is hence critical to identify high risk areas, potential hosts, and adequate prevention strategies. 


\section{Acknowledgments}

We thank Paula Belen Zavala Guerrero for her illustration artwork in Figures 1-3.

\section{Author contributions}

ROF \& GS: Conceptualization, Writing - Review and editing. PMD, RAM, ECB \& ORC: Writing - Review.

\section{References}

Agudelo-Romero, P., Carbonell, P., Perez-Amador, M.A., Elena, S.F., 2008. Virus Adaptation by Manipulation of Host's Gene Expression. PLoS One 3, 1-7. https://doi. org/10.1371/journal.pone.0002397

Amanat, F., Krammer, F., 2020. SARS-CoV-2 Vaccines: Status Report. Immunity 52, 583-589. https://doi.org/10.1016/j.immuni.2020.03.007

Anderson, R.P., 2012. Harnessing the world's biodiversity data: promise and peril in ecological niche modeling of species distributions. Ann. N. Y. Acad. Sci. 1260, 66-80. https://doi.org/10.1111/j.1749-6632.2011.06440.x

Ang, B.S.P., Lim, T.C.C., Wang, L., 2018. Nipah Virus Infection. J. Clin. Microbiol. 56, e01875-17. https://doi.org/10.1128/JCM.01875-17

Anthony, S. J., Epstein, J.H., Murray, K.A., Navarrete-Macias, I., Zambrana-Torrelio, C.M., etal., 2013. A Strategy To Estimate Unknown Viral Diversity in Mammals. MBio 4, e00598-13. https://doi.org/10.1128/mBio.00598-13

Anthony, S.J., Ojeda-Flores, R., Rico-Chávez, O., Navarrete-Macias, l., Zambrana-Torrelio, et al., 2013. Coronaviruses in bats from Mexico. J. Gen. Virol. 94, 10281038. https://doi.org/10.1099/vir.0.049759-0

Anthony, S.J., Johnson, C.K., Greig, D.J., Kramer, S., Che, X., et al., 2017. Global patterns in coronavirus diversity. Virus Evol. 3. https://doi.org/10.1093/ve/vex012

Barrett, M.A., Bouley, T.A., Stoertz, A.H., Stoertz, R.W., 201 1. Integrating a One Health approach in education to address global health and sustainability challenges. Front. Ecol. Environ. 9, 239-245. https://doi.org/10.1890/090159

Beck, J., Böller, M., Erhardt, A., Schwanghart, W., 2014. Spatial bias in the GBIF database and its effect on modeling species' geographic distributions. Ecol. Inform. 19, 10-15. https://doi.org/https://doi.org/10.1016/j.ecoinf.2013.11.002

Behdenna, A., Lembo, T., Calatayud, O., Cleaveland, S., Halliday, et al., 2019. Transmission ecology of canine parvovirus in a multi-host, multi-pathogen system. Proc. R. Soc. B Biol. Sci. 286, 20182772. https://doi.org/10.1098/rspb.2018.2772

Bengis, R.G., Leighton, F.A., Fischer, J.R., Artois, M., Mörner, T., Tate, C.M., 2004. The role of wildlife in emerging and re-emerging zoonoses. Rev. Sci. Tech. 23, 497-511.

Boots, M., Best, A., Miller, M.R., White, A., 2009. The role of ecological feedbacks in the evolution of host defence: what does theory tell us? Philos. Trans. R. Soc. B Biol. Sci. 364, 27-36. https://doi.org/10.1098/rstb.2008.0160

Brian, D.A., Baric, R.S., 2005. Coronavirus genome structure and replication. Curr. Top. Microbiol. Immunol. 287, 1-30. https://doi.org/10.1007/3-540-26765-4_1

Carroll,S.P.,Hendry,A.P., Reznick,D.N.,Fox,C.W., 2007.Evolutiononecologicaltime-scales. Funct. Ecol. 21, 387-393. https://doi.org/10.1111/j.1365-2435.2007.01289.x

Christou, L., 2011 . The global burden ofbacterial and viral zoonoticinfections. Clin. Microbiol. Infect. 17, 326-330. https://doi.org/10.1111/j.1469-0691.2010.03441.x 
Chu, Y.-K., Owen, R.D., Jonsson, C.B., 2011. Phylogenetic exploration of hantaviruses in paraguay reveals reassortment and host switching in South America. Virol. J. 8, 399. https://doi.org/10.1186/1743-422X-8-399

Cobb, R.C., Filipe, J.A.N., Meentemeyer, R.K., Gilligan, C.A., Rizzo, D.M., 2012. Ecosystem transformation by emerging infectious disease: loss of large tanoak from California forests. J. Ecol. 100, 712-722. https://doi. org/10.1111/j.1365-2745.2012.01960.x

Cook R., Karesh W., S.O., 2004. One World, One Health: Building Interdisciplinary Bridges to Health in a Globalized World. Wildlife Conservation Society, Bronx, New York, USA (2004) [WWW Document]. Available from: http://www.oneworldonehealth.org/sept2004/owoh_sept04.html.

Corporation, B.B., 2003. Animals suffer in the war on SARS.

Cressler, C.E., McLeod, D. V, Rozins, C., Van Den Hoogen, J., Day, T., 2016. The adaptive evolution of virulence: a review of theoretical predictions and empirical tests. Parasitology 143, 915-930. https://doi.org/10.1017/S003118201500092X

Cui, J., Li, F., Shi, Z.-L., 2019. Origin and evolution of pathogenic coronaviruses. Nat. Rev. Microbiol. 17, 181-192. https://doi.org/10.1038/s41579-018-0118-9

Cunningham, A.A., Daszak, P., Wood, J.L.N., 2017. One Health, emerging infectious diseases and wildlife: two decades of progress? Philos. Trans. R. Soc. London. Ser. B, Biol. Sci. 372. https://doi.org/10.1098/rstb.2016.0167

da Silva Candido, D., Watts, A., Abade, L., Kraemer, M.U.G., Pybus, O.G., et al., 2020. Routes for COVID-19 importation in Brazil. medRxiv 2020.03.15.20036392. https://doi.org/10.1101/2020.03.15.20036392

Daily, G.C., Ceballos, G., Pacheco, J., Suzán, G., Sánchez-Azofeifa, A., 2003. Countryside Biogeography of Neotropical Mammals: Conservation Opportunities in Agricultural Landscapes of Costa Rica. Conserv. Biol. 17, 1814-1826. https:// doi.org/10.1111/j.1523-1739.2003.00298.x

Daszak, P., Cunningham, A.A., Hyatt, A.D., 2000. Emerging Infectious Diseases of Wildlife-- Threats to Biodiversity and Human Health. Science (80). 287, 443 LP - 449. https://doi.org/10.1126/science.287.5452.443

Daszak, P., Cunningham, A.A., Hyatt, A.D., 2001. Anthropogenic environmental change and the emergence of infectious diseases in wildlife. Acta Trop. 78, 103-1 16. https://doi.org/https://doi.org/10.1016/S0001-706X(00)00179-0

Davies, T.J., Pedersen, A.B., 2008. Phylogeny and geography predict pathogen community similarity in wild primates and humans. Proc. R. Soc. B Biol. Sci. 275, 1695-1701. https://doi.org/10.1098/rspb.2008.0284

Day, T., Proulx, S.R., 2004. A General Theory for the Evolutionary Dynamics of Virulence. Am. Nat. 163, E40-E63. https://doi.org/10.1086/382548

de Groot RJ, et al., 2011. Coronaviridae, in: King AMQ, Adams MJ, Carstens EB, L. (Ed.), Virus Taxonomy: Ninth Report of the International Committee on Taxonomy of Viruses, International Union of Microbiological Societies, Virology Division. Elsevier Academic Press, London, United Kingdom, p. 806-828.

de Vries, A.A.F., Horzinek, M.C., Rottier, P.J.M., de Groot, R.J., 1997. The Genome Organization of the Nidovirales: Similarities and Differences between Arteri-, Toro-, and Coronaviruses. Semin. Virol. 8, 33-47. https://doi.org/10.1006/ smvy.1997.0104 
Denef, V.J., Mueller, R.S., Banfield, J.F., 2010. AMD biofilms: using model communities to study microbial evolution and ecological complexity in nature. ISME J. 4, 599-610. https://doi.org/10.1038/ismej.2009.158

Deng, X., Gu, W., Federman, S., du Plessis, L., Pybus, O.G., Faria, N., et al., 2020. Genomic surveillance reveals multiple introductions of SARS-CoV-2 into Northern California. Science (80-. ). eabb9263. https://doi.org/10.1126/science. abb9263

Diffendorfer, J.E., Gaines, M.S., Holt, R.D., 1995. Habitat Fragmentation and Movements of Three Small Mammals (Sigmodon, Microtus, and Peromyscus). Ecology 76, 827-839. https://doi.org/10.2307/1939348

Drexler, J.F., Corman, V.M., Drosten, C., 2014. Ecology, evolution and classification of bat coronaviruses in the aftermath of SARS. Antiviral Res. 101, 45-56. https:// doi.org/10.1016/j.antiviral.2013.10.013

Drosten, C., Günther, S., Preiser, W., van der Werf, S., Brodt, H.-R., et al., 2003. Identification of a Novel Coronavirus in Patients with Severe Acute Respiratory Syndrome. N. Engl. J. Med. 348, 1967-1976. https://doi.org/10.1056/ NEJMoa030747

Durães-Carvalho, R., Caserta, L.C., Barnabé, A.C.S., Martini, M.C., Simas, P.V.M., et al., 2015. Phylogenetic and phylogeographic mapping of the avian coronavirus spike protein-encoding gene in wild and synanthropic birds. Virus Res. 201, 101-112. https://doi.org/https://doi.org/10.1016/j.virusres.2015.03.002

Ellis, E.C., Klein Goldewijk, K., Siebert, S., Lightman, D., Ramankutty, N., 2010. Anthropogenic transformation of the biomes, 1700 to 2000. Glob. Ecol. Biogeogr. 19, 589-606. https://doi.org/10.1111/j.1466-8238.2010.00540.x

Ermonval, M., Baychelier, F., Tordo, N., 2016. What Do We Know about How Hantaviruses Interact with Their Different Hosts? Viruses 8, 223. https://doi. org/10.3390/v8080223

Errecaborde, K.M., Macy, K.W., Pekol, A., Perez, S., O'Brien, M.K., et al., 2019. Factors that enable effective One Health collaborations - A scoping review of the literature. PLoS One 14, 1-24. https://doi.org/10.1371/journal.pone.0224660

Friant, S., Ayambem, W.A., Alobi, A.O., Ifebueme, N.M., Otukpa, O.M., et al., 2020. Eating Bushmeat Improves Food Security in a Biodiversity and Infectious Disease "Hotspot." Ecohealth 17, 125-138. https://doi.org/10.1007/ s10393-020-01473-0

Gao, F., Bailes, E., Robertson, D.L., Chen, Y., Rodenburg, C.M., et al., 1999. Origin of HIV-1 in the chimpanzee Pan troglodytes. Nature 397, 436-441. https://doi. org/10.1038/17130

Gibbs, S.E.J., Gibbs, E.P.J., 2013. The Historical, Present, and Future Role of Veterinarians in One Health, in: Mackenzie, J.S., Jeggo, M., Daszak, P., Richt, J.A. (Eds.), One Health: The Human-Animal-Environment Interfaces in Emerging Infectious Diseases: The Concept and Examples of a One Health Approach. Springer Berlin Heidelberg, Berlin, Heidelberg, p. 31-47. https://doi. org/10.1007/82_2012_259

Gloza-Rausch, F., Ipsen, A., Seebens, A., Göttsche, M., Panning, M., et al., 2008. Detection and prevalence patterns of group I coronaviruses in bats, northern Germany. Emerg. Infect. Dis. 14, 626-631. https://doi.org/10.3201/eid1404.071439 
Goldstein, S.A., Weiss, S.R., 2017. Origins and pathogenesis of Middle East respiratory syndrome-associated coronavirus: recent advances. F1000Research 6, 1628. https://doi.org/10.12688/f1000research.11827.1

Gong, S., Bao, L., 2018. The battle against SARS and MERS coronaviruses: Reservoirs and Animal Models. Anim. Model. Exp. Med. 1, 125-133. https://doi. org/10.1002/ame2.12017

Gottdenker, N.L., Streicker, D.G., Faust, C.L., Carroll, C.R., 2014. Anthropogenic Land Use Change and Infectious Diseases: A Review of the Evidence. Ecohealth 11, 619-632. https://doi.org/10.1007/s10393-014-0941-z

Halpin, K., Young, P.L., Field, H.E., Mackenzie, J.S., 2000. Isolation of Hendra virus from pteropid bats: a natural reservoir of Hendra virus. J. Gen. Virol. 81, 19271932. https://doi.org/https://doi.org/10.1099/0022-1317-81-8-1927

Hassell, J.M., Begon, M., Ward, M.J., Fèvre, E.M., 2017. Urbanization and Disease Emergence: Dynamics at the Wildlife-Livestock-Human Interface. Trends Ecol. Evol. 32, 55-67. https://doi.org/https://doi.org/10.1016/j.tree.2016.09.012

Hayman, D.T.S., 2016. Bats as Viral Reservoirs. Annu. Rev. Virol. 3, 77-99. https:// doi.org/10.1146/annurev-virology-1 10615-042203

Heinrich, S. et al., 2017. The Global Trafficking of Pangolins: A Comprehensive Summary of Seizures and Trafficking Routes from 2010-2015 (TRAFFIC, 2017).

Hoberg, E.P., Brooks, D.R., 2015. Evolution in action: climate change, biodiversity dynamics and emerging infectious disease. Philos. Trans. R. Soc. Lond. B. Biol. Sci. 370, 20130553. https://doi.org/10.1098/rstb.2013.0553

Hunt, D.E., David, L.A., Gevers, D., Preheim, S.P., Alm, E.J., Polz, M.F., 2008. Resource Partitioning and Sympatric Differentiation Among Closely Related Bacterioplankton. Science (80). 320, 1081 LP - 1085. https://doi.org/10.1126/ science. 1157890

Iwasa, Y., Michor, F., Nowak, M.A., 2004. Evolutionary dynamics of invasion and escape. J. Theor. Biol. 226, 205-214. https://doi.org/https://doi.org/10.1016/j. jtbi.2003.08.014

Jackwood, M.W., 2006. The Relationship of Severe Acute Respiratory Syndrome Coronavirus with Avian and Other Coronaviruses. Avian Dis. 50, 315-320. https://doi.org/10.1637/7612-042006R. 1

Johnson, P.T.J., de Roode, J.C., Fenton, A., 2015. Why infectious disease research needs community ecology. Science 349, 1259504. https://doi.org/10.1126/ science. 1259504

Jones, K.E., Patel, N.G., Levy, M.A., Storeygard, A., Balk, D., Gittleman, J.L., Daszak, P., 2008. Global trends in emerging infectious diseases. Nature 451, 990-993. https://doi.org/10.1038/nature06536

Kelly, T.R., Karesh, W.B., Johnson, C.K., Gilardi, K.V.K., Anthony, S.J., et al., 2017. One Health proof of concept: Bringing a transdisciplinary approach to surveillance for zoonotic viruses at the human-wild animal interface. Prev. Vet. Med. 137, 112-118. https://doi.org/https://doi.org/10.1016/j.prevetmed.2016.11.023

Kulkarni, D.D., Tosh, C., Venkatesh, G., Senthil Kumar, D., 2013. Nipah virus infection: current scenario. Indian J. Virol. 24, 398-408. https://doi.org/10.1007/ s13337-013-0171-y

Lam, T.T.Y., Jia, N., Zhang, Y.-W., Shum, M.H.-H., Jiang, J.-F., et al., 2020. Identifying SARS-CoV-2-related coronaviruses in Malayan pangolins. Nature. https://doi. org/10.1038/s41586-020-2169-0 
Lanzagorta-Valencia, K., Fernández-Méndez, J.I., Medellín, R.A., Rodas-Martínez, A.Z., Avila-Flores, R., 2019. Landscape and cattle management attributes associated with the incidence of Desmodus rotundus attacks on cattle. Ecosistemas y Recur. Agropecu. 7, 1-10. https://doi.org/10.19136/era.a7n1.2164

Lau, M.W.-N., Fellowes, J.R., Chan, B.P.L., 2010. Carnivores (Mammalia: Carnivora) in South China: a status review with notes on the commercial trade. Mamm. Rev. 40, 247-292. https://doi.org/10.1111/j.1365-2907.2010.00163.x

Lau, S.K.P., Woo, P.C.Y., Li, K.S.M., Huang, Y., Tsoi, H.-W., et al., 2005. Severe acute respiratory syndrome coronavirus-like virus in Chinese horseshoe bats. Proc. Natl. Acad. Sci. 102, 14040-14045. https://doi.org/10.1073/pnas.0506735102

Lei, B.R., Olival, K.J., 2014. Contrasting Patterns in Mammal-Bacteria Coevolution: Bartonella and Leptospira in Bats and Rodents. PLoS Negl. Trop. Dis. 8, 1-11. https://doi.org/10.1371/journal.pntd.0002738

Lemey, P., Hong, S., Hill, V., Baele, G., Poletto, C., et al., 2020. Accommodating individual travel history, global mobility, and unsampled diversity in phylogeography: a SARS-CoV-2 case study. bioRxiv 2020.06.22.165464. https://doi. org/10.1101/2020.06.22.165464

Leroy, E.M., Rouquet, P., Formenty, P., Souquière, S., Kilbourne, et al., 2004. Multiple Ebola Virus Transmission Events and Rapid Decline of Central African Wildlife. Science (80). 303, 387 LP - 390. https://doi.org/10.1126/science.1092528

Lewis, N.D., 2005. Is the Social-Ecological Framework Useful in Understanding Infectious Diseases? The Case of HIV/AIDS. Ecohealth 2, 343-348. https://doi. org/10.1007/s10393-005-8477-x

Li, W., Shi, Z., Yu, M., Ren, W., Smith, C., et al., 2005. Bats Are Natural Reservoirs of SARS-like Coronaviruses. Science (80-). 310, 676-679.

Liu, P., Chen, W., Chen, J.-P., 2019. Viral Metagenomics Revealed Sendai Virus and Coronavirus Infection of Malayan Pangolins (Manis javanica). Viruses 11. https://doi.org/10.3390/v11110979

Luis, A. D., Hayman, D. T. S., O'Shea, T. J., Cryan, P. M., Gilbert, A. T., Pulliam, J. R., et al. (2013). A comparison of bats and rodents as reservoirs of zoonotic viruses: are bats special? Proc. R. Soc. B 280:20122753. doi: 10.1098/rspb.2012.2753

López-Pérez, A.M., Moreno, K., Chaves, A., Ibarra-Cerdeña, C.N., Rubio, A., et al., 2019. Carnivore Protoparvovirus 1 at the Wild-Domestic Carnivore Interface in Northwestern Mexico. Ecohealth 16, 502-511. https://doi.org/10.1007/ s10393-019-01436-0

Luk, H.K.H., Li, X., Fung, J., Lau, S.K.P., Woo, P.C.Y., 2019. Molecular epidemiology, evolution and phylogeny of SARS coronavirus. Infect. Genet. Evol. J. Mol. Epidemiol. Evol. Genet. Infect. Dis. 71, 21-30. https://doi.org/10.1016/j. meegid.2019.03.001

Mackenstedt, U., Jenkins, D., Romig, T., 2015. The role of wildlife in the transmission of parasitic zoonoses in peri-urban and urban areas. Int. J. Parasitol. Parasites Wildl. 4, 71-79. https://doi.org/https://doi.org/10.1016/j.jppaw.2015.01.006

Martínez-Duque, P., 2017. Diversidad de Coronavirus en murciélagos del límite Neártico-Neotropical en México. UNAM.

Masters, P.S., 2006. The Molecular Biology of Coronaviruses, in: Advances in Virus Research. Academic Press, pp. 193-292. https://doi.org/https://doi. org/10.1016/S0065-3527(06)66005-3 
Mavian, C., Pond, S.K., Marini, S., Magalis, B.R., Vandamme, et al., 2020. Sampling bias and incorrect rooting make phylogenetic network tracing of SARS-COV-2 infections unreliable. Proc. Natl. Acad. Sci. 117, 12522 LP - 12523. https://doi. org/10.1073/pnas.2007295117

May, R.M., McLean, A.R., Pattison, J., Weiss, R.A., Bell, D., Roberton, S., Hunter, P.R., 2004. Animal origins of SARS coronavirus: possible links with the international trade in small carnivores. Philos. Trans. R. Soc. London. Ser. B Biol. Sci. 359, 1107-1114. https://doi.org/10.1098/rstb.2004.1492

Milholland, M.T., Castro-Arellano, I., Suzán, G., Garcia-Peña, G.E., Lee, T.E.,et al., 2018. Global Diversity and Distribution of Hantaviruses and Their Hosts. Ecohealth 15, 163-208. https://doi.org/10.1007/s 10393-017-1305-2

Mohd, H.A., Al-Tawfiq, J.A., Memish, Z.A., 2016. Middle East Respiratory Syndrome Coronavirus (MERS-CoV) origin and animal reservoir. Virol. J. 13, 87. https://doi. org/10.1186/s12985-016-0544-0

Morens, D.M., Folkers, G.K., Fauci, A.S., 2004. The challenge of emerging and re-emerging infectious diseases. Nature 430, 242-249. https://doi. org/10.1038/nature02759

Morse, S.S., 1995. Factors in the Emergence of Infectious Diseases. Emerg. Infect. Dis. J. 1, 7. https://doi.org/10.3201/eid0101.950102

Murray, K.A., Preston, N., Allen, T., Zambrana-Torrelio, C., Hosseini, P.R., Daszak, P., 2015. Global biogeography of human infectious diseases. Proc. Natl. Acad. Sci. 112, 12746 LP - 12751. https://doi.org/10.1073/pnas.1507442112

Nieto-Rabiela, F., Suzán, G., Wiratsudakul, A., Rico-Chávez, O., 2018. Viral metacommunities associated to bats and rodents at different spatial scales. Community Ecol. 19, 168-175. https://doi.org/10.1556/168.2018.19.2.9

Nieto-Rabiela, F., Wiratsudakul, A., Suzán, G., Rico-Chávez, O., 2019. Viral networks and detection of potential zoonotic viruses in bats and rodents: A worldwide analysis. Zoonoses Public Health 66, 655-666. https://doi.org/10.1111/ zph. 12618

Ojeda-Flores, R., 2015. Coronavirus en murciélagos neotropicales en México: prevalencia, filogenia y coevolución. UNAM.

Ortega, J., Arita, H.T., 1998. Neotropical-Nearctic Limits in Middle America as Determined by Distributions of Bats. J. Mammal. 79, 772-783. https://doi. org/10.2307/1383088

Osborne, C., Cryan, P.M., O'Shea, T.J., Oko, L.M., Ndaluka, C., et al., 201 1. Alphacoronaviruses in New World Bats: Prevalence, Persistence, Phylogeny, and Potential for Interaction with Humans. PLoS One 6, 1-11. https://doi.org/10.1371/journal.pone.0019156

Paige, S.B., Bleecker, J., Mayer, J., Goldberg, T., 2017. Spatial Overlap Between People and Non-human Primates in a Fragmented Landscape. Ecohealth 14, 88-99. https://doi.org/10.1007/s10393-016-1 194-9

Papkou, A., Gokhale, C.S., Traulsen, A., Schulenburg, H., 2016. Host-parasite coevolution: why changing population size matters. Zoology 119, 330-338. https:// doi.org/https://doi.org/10.1016/j.zool.2016.02.001

Patz, J.A., Daszak, P., Tabor, G.M., Aguirre, A.A., Pearl, M., et al., 2004. Unhealthy landscapes: Policy recommendations on land use change and infectious disease emergence. Environ. Health Perspect. 112, 1092-1098. https://doi. org/10.1289/ehp.6877 
Pavlin, B.I., Schloegel, L.M., Daszak, P., 2009. Risk of importing zoonotic diseases through wildlife trade, United States. Emerg. Infect. Dis. 15, 1721-1726. https://doi.org/10.3201/eid1511.090419

Perlman, S., 2013. The Middle East Respiratory Syndrome-How Worried Should We Be? MBio 4, e00531-13. https://doi.org/10.1128/mBio.00531-13

Peterson, A.T., Bauer, J.T., Mills, J.N., 2004. Ecologic and geographic distribution of filovirus disease. Emerg. Infect. Dis. 10, 40-47. https://doi.org/10.3201/ eid 1001.030125

Pfefferle, S., Oppong, S., Drexler, J.F., Gloza-Rausch, F., Ipsen, A., et al., 2009. Distant relatives of severe acute respiratory syndrome coronavirus and close relatives of human coronavirus 229E in bats, Ghana. Emerg. Infect. Dis. 15, 1377-1384. https://doi.org/10.3201/eid1509.090224

Plowright, R.K., Eby, P., Hudson, P.J., Smith, I.L., Westcott, D., et al., 2015. Ecological dynamics of emerging bat virus spillover. Proc. R. Soc. B Biol. Sci. 282, 20142124. https://doi.org/10.1098/rspb.2014.2124

Plowright, R.K., Parrish, C.R., McCallum, H., Hudson, P.J., Ko, A.I., et al., 2017. Pathways to zoonotic spillover. Nat. Rev. Microbiol. 15, 502-510. https://doi. org/10.1038/nrmicro.2017.45

Poon, L.L.M., Chu, D.K.W., Chan, K.H., Wong, O.K., Ellis, T.M., et al., 2005. Identification of a novel coronavirus in bats. J. Virol. 79, 2001-2009. https://doi. org/10.1128/JVI.79.4.2001-2009.2005

Quinn PJ, et al., 2011. Veterinary Microbiology and Microbial Disease, 2nd Edition, 2nd ed. Wiley-Blackwell.

Rabaan, A.A., Al-Ahmed, S.H., Bazzi, A.M., Al-Tawfiq, J.A., 2017. Dynamics of scientific publications on the MERS-CoV outbreaks in Saudi Arabia. J. Infect. Public Health 10, 702-710. https://doi.org/https://doi.org/10.1016/j.jiph.2017.05.005

Reperant, L.A., 2010. Applying the theory of island biogeography to emerging pathogens: toward predicting the sources of future emerging zoonotic and vector-borne diseases. Vector Borne Zoonotic Dis. 10, 105-110. https://doi. org/10.1089/vbz.2008.0208

Rico-Chávez O, Ojeda-Flores R, Sotomayor-Bonilla J, Zambrana-Torrelio C, Loza Rubio $\mathrm{E}$, et al., 2015. Viral diversity of bat communities in human-dominated landscapes in Mexico. Vet. México OA 2, 1-22.

Rosen, G.E., Smith, K.F., 2010. Summarizing the Evidence on the International Trade in Illegal Wildlife. Ecohealth 7, 24-32. https://doi.org/10.1007/ s10393-010-0317-y

Rubio, A. V, Ávila-Flores, R., Suzán, G., 2014. Responses of small mammals to habitat fragmentation: epidemiological considerations for rodent-borne hantaviruses in the Americas. Ecohealth 11, 526-533. https://doi.org/10.1007/ s10393-014-0944-9

Scheiner, S.M., 2009. The Intersection of the Sciences of Biogeography and Infectious Disease Ecology. Ecohealth 6, 483-488. https://doi.org/10.1007/ s10393-010-0298-x

Schountz, T., 2014. Immunology of bats and their viruses: challenges and opportunities. Viruses 6, 4880-4901. https://doi.org/10.3390/v6124880

Smith, I., Wang, L.-F., 2013. Bats and their virome: an important source of emerging viruses capable of infecting humans. Curr. Opin. Virol. 3, 84-91. https://doi.org/ https://doi.org/10.1016/j.coviro.2012.11.006 
Song, H.-D., Tu, C.-C., Zhang, G.-W., Wang, S.-Y., Zheng, K., et al., 2005. Cross-host evolution of severe acute respiratory syndrome coronavirus in palm civet and human. Proc. Natl. Acad. Sci. U. S. A. 102, 2430 LP - 2435. https://doi. org/10.1073/pnas.0409608102

Suzán, G., Ceballos, G., 2005. The role of feral mammals on wildlife infectious disease prevalence in two nature reserves within Mexico City limits. J. Zoo Wildl. Med. 36, 479-484. https://doi.org/10.1638/04-078.1

Suzán, G., García-Peña, G.E., Castro-Arellano, I., Rico, O., Rubio, A. V, et al., 2015. Metacommunity and phylogenetic structure determine wildlife and zoonotic infectious disease patterns in time and space. Ecol. Evol. 5, 865-873. https://doi. org/10.1002/ece3.1404

Tang, X.C., Zhang, J.X., Zhang, S.Y., Wang, P., Fan, X.H., et al., 2006. Prevalence and genetic diversity of coronaviruses in bats from China. J. Virol. 80, 7481-7490. https://doi.org/10.1128/JVI.00697-06

Taylor, L.H., Latham, S.M., Woolhouse, M.E., 2001. Risk factors for human disease emergence. Philos. Trans. R. Soc. Lond. B. Biol. Sci. 356, 983-989. https://doi. org/10.1098/rstb.2001.0888

Torres-Pérez, F., Navarrete-Droguett, J., Aldunate, R., Yates, T.L., Mertz, G.J., et al., 2004. Peridomestic small mammals associated with confirmed cases of human hantavirus disease in southcentral Chile. Am. J. Trop. Med. Hyg. 70, 305-309.

Urban, D.L., 2006. Landscape Ecology, in: Encyclopedia of Environmetrics. American Cancer Society. https://doi.org/10.1002/9780470057339.val005

Utrera, A., Duno, G., 2007. Preferencias de hãl'bitat de Sigmodon alstoni y Zygodontomys brevicauda (Rodentia, Cricetidae) en agroecosistemas de los llanos de Venezuela. Interciencia 32, 471-476.

VanWormer, E., Fritz, H., Shapiro, K., Mazet, J.A.K., Conrad, P.A., 2013. Molecules to modeling: Toxoplasma gondii oocysts at the human-animal-environment interface. Comp. Immunol. Microbiol. Infect. Dis. 36, 217-231. https://doi.org/ https://doi.org/10.1016/j.cimid.2012.10.006

Vijaykrishna, D., Smith, G.J.D., Zhang, J.X., Peiris, J.S.M., Chen, H., Guan, Y., 2007. Evolutionary Insights into the Ecology of Coronaviruses. J. Virol. 81, 4012 LP 4020. https://doi.org/10.1128/JVI.02605-06

Walsh, E.E., Shin, J.H., Falsey, A.R., 2013. Clinical impact of human coronaviruses 229E and OC43 infection in diverse adult populations. J. Infect. Dis. 208, 1634-1642. https://doi.org/10.1093/infdis/jit393

Webster, J.P., Gower, C.M., Knowles, S.C.L., Molyneux, D.H., Fenton, A., 2016. One health - an ecological and evolutionary framework for tackling Neglected Zoonotic Diseases. Evol. Appl. 9, 313-333. https://doi.org/10.1111/eva. 12341

White, R.J., Razgour, O., 2020. Emerging zoonotic diseases originating in mammals: a systematic review of effects of anthropogenic land-use change. Mamm. Rev. 50, 336-352. https://doi.org/10.1111/mam. 12201

WHO, 2020. Coronavirus disease 2019 (COVID-19) situation reports [WWW Document].

WHO, 2019. Middle East respiratory syndrome coronavirus (MERS-CoV) [WWW Document].

WHO, 2003. SARS outbreak contained worldwide [WWW Document].

Wiens, J.A., Stenseth, N.C., Van Horne, B., Ims, R.A., 1993. Ecological Mechanisms and Landscape Ecology. Oikos 66, 369-380. https://doi.org/10.2307/3544931 
Wilcox, B.A., Colwell, R.R., 2005. Emerging and Reemerging Infectious Diseases: Biocomplexity as an Interdisciplinary Paradigm. Ecohealth 2, 244. https://doi. org/10.1007/s 10393-005-8961-3

Woo, P.C.Y., Lau, S.K.P., Yip, C.C.Y., Huang, Y., Tsoi, H.-W., Chan, K.-H., Yuen, K.-Y., 2006. Comparative analysis of 22 coronavirus HKU1 genomes reveals a novel genotype and evidence of natural recombination in coronavirus HKU1. J. Virol. 80, 7136-7145. https://doi.org/10.1128/JVI.00509-06

Woo, P.C.Y., Lau, S.K.P., Huang, Y., Yuen, K.-Y., 2009. Coronavirus diversity, phylogeny and interspecies jumping. Exp. Biol. Med. (Maywood). 234, 1117-1127. https://doi.org/10.3181/0903-MR-94

Woo, P.C.Y., Lau, S.K.P., Lam, C.S.F., Lau, C.C.Y., Tsang, A.K.L., et al., 2012a. Discovery of Seven Novel Mammalian and Avian Coronaviruses in the Genus Deltacoronavirus Supports Bat Coronaviruses as the Gene Source of Alphacoronavirus and Betacoronavirus and Avian Coronaviruses as the Gene Source of Gammacoronavirus and Deltacoronavirus. J. Virol. 86, 3995 LP - 4008. https://doi. org/10.1128/JVI.06540-11

Woo, P.C.Y., Lau, S.K.P., Lam, C.S.F., Lau, C.C.Y., Tsang, A.K.L., et al., 2012b. Discovery of seven novel Mammalian and avian coronaviruses in the genus deltacoronavirus supports bat coronaviruses as the gene source of alphacoronavirus and betacoronavirus and avian coronaviruses as the gene source of gammacoronavirus and deltacoronavi. J. Virol. 86, 3995-4008. https://doi.org/10.1128/ JVI.06540-11

Woolhouse, M.E.J., Taylor, L.H., Haydon, D.T., 2001. Population Biology of Multihost Pathogens. Science (80). 292, 1109 LP - 1112. https://doi.org/10.1126/ science. 1059026

Wyler, L.S., Sheikh, P.A., 2016. International illegal trade in wildlife: Threats and U.S. policy, Combating Wildlife Trafficking: National Strategy, Implementation Plan and Restrictions on Elephant Ivory Trade. Report for Congress.

Xiao, K., Zhai, J., Feng, Y., Zhou, N., Zhang, X., et al., 2020. Isolation of SARS-CoV-2related coronavirus from Malayan pangolins. Nature. https://doi.org/10.1038/ s41586-020-2313-x

Xu, R.-H., He, J.-F., Evans, M.R., Peng, G.-W., Field, H.E., et al., 2004. Epidemiologic clues to SARS origin in China. Emerg. Infect. Dis. 10, 1030-1037. https://doi. org/10.3201/eid1006.030852

Yahnke, C.J. (Universit. of W.D. of B. and M. of N.H., 2006. Habitat use and natural history of small mammals in the Central Paraguayan Chaco. Mastozoología Neotrop.

Zaki, A.M., van Boheemen, S., Bestebroer, T.M., Osterhaus, A.D.M.E., Fouchier, R.A.M., 2012. Isolation of a Novel Coronavirus from a Man with Pneumonia in Saudi Arabia. N. Engl. J. Med. 367, 1814-1820. https://doi.org/10.1056/ NEJMoa 1211721

Zhou, H., Chen, X., Hu, T., Li, J., Song, H., et al., 2020. A Novel Bat Coronavirus Closely Related to SARS-CoV-2 Contains Natural Insertions at the S1/S2 Cleavage Site of the Spike Protein. Curr. Biol. 30, 2196-2203.e3. https://doi.org/https://doi. org/10.1016/j.cub.2020.05.023

Zhou, P., Yang, X.-L., Wang, X.-G., Hu, B., Zhang, L., Zhang, W., et al., 2020. A pneumonia outbreak associated with a new coronavirus of probable bat origin. Nature 579, 270-273. https://doi.org/10.1038/s41586-020-2012-7. 